\title{
Perceptions of medical students towards the practice of professionalism at the Arabian Gulf University
}

\author{
Haifa Mohammed Saleh Al Gahtani ${ }^{1}$, Haitham Ali Jahrami ${ }^{1}$ and Henry J. Silvermann ${ }^{2 *}$
}

\begin{abstract}
Background: To enhance the development of a curriculum in professionalism for medical students, the aim of this research was to evaluate medical students' responses regarding professionalism teaching and behaviors in their clinical experience at the Arabian Gulf University (AGU).

Methods: A retrospective cross-sectional, questionnaire-based study involving Year 5 medical students at the AGU. We used a "climate of professionalism" survey that consisted of two parts. The first part asked students to rate their perceptions of the frequency of professionalism practices of their peers (medical students), residents, and faculty. The response choices included: "mostly", "sometimes", and "rarely". The second part asked the students to assess their perceptions of the professionalism teaching and behaviors of the faculty. The response choices included: "mostly", "sometimes", and "rarely". We calculated an overall score for the responses in both parts of the questionnaire by assigning 3, 2, and 1 points to the response choices, respectively. We also calculated subscale scores reflecting different professionalism constructs. We used descriptive statistics and a one-way Analysis of Variance (ANOVA) followed by multiple testing comparisons with Bonferroni correction to examine pairwise comparisons. A $p<0.05$ was considered statistically significant.
\end{abstract}

Results: The mean total scores of participants' ratings of professional behaviors of medical students, residents, and faculty for each academic year were approximately $60 \%$ of the total maximum score. The mean total scores of participants' rating of faculty's teaching and modeling behaviors concerning professionalism were approximately $58 \%$ of the maximum score. Compared with similar studies performed in the Arab Region, ratings regarding professional teaching and modeling of professionalism were lower.

Conclusion: We recommend the further evaluation of professionalism teaching and behaviors at the AGU and further discussions regarding curriculum reform.

Keywords: Professionalism, Medical students, Teaching professionalism, Behaviors

\section{Background}

There has been an increased emphasis on teaching medical professionalism in the last decade due to public dissatisfaction with the performance of the medical profession [1]. As patients entrust their health to health

\footnotetext{
* Correspondence: hsilverm@som.umaryland.edu

${ }^{2}$ Department of Medicine, University of Maryland Baltimore, Baltimore, MD 21201, USA

Full list of author information is available at the end of the article
}

care providers, graduates will find professionalism an essential quality to complement their biomedical knowledge and clinical skills. Studies have shown that medical professionalism is associated with improvement in patient-physician relationships, patient and professional satisfaction, and healthcare outcomes [2].

Professionalism refers to a collection of values, attitudes, behaviors, and relationships that act as the foundation of the healthcare profession's contract with

(c) The Author(s). 2021 Open Access This article is licensed under a Creative Commons Attribution 4.0 International License, which permits use, sharing, adaptation, distribution and reproduction in any medium or format, as long as you give appropriate credit to the original author(s) and the source, provide a link to the Creative Commons licence, and indicate if changes were made. The images or other third party material in this article are included in the article's Creative Commons licence, unless indicated otherwise in a credit line to the material. If material is not included in the article's Creative Commons licence and your intended use is not permitted by statutory regulation or exceeds the permitted use, you will need to obtain permission directly from the copyright holder. To view a copy of this licence, visit http://creativecommons.org/licenses/by/4.0/ The Creative Commons Public Domain Dedication waiver (http://creativecommons.org/publicdomain/zero/1.0/) applies to the data made available in this article, unless otherwise stated in a credit line to the data. 
society [3]. The concept of medical professionalism has evolved from the earliest teachings of Hippocrates, [4] who described physician behaviors expected of them and Alī al-Ruhāwī, [5] who defined the characteristics of a virtuous physician, to the more recent charter of medical professionalism that outlined and discussed discrete principles [6]. The importance of professionalism to medical students represents a commitment to professional skills and attitudes that they will acquire reliably and lead to public trust in the medical profession.

An established framework that lists the attributes of medical professionalism includes the American.

Board of Internal Medicine (ABIM), which consists of six domains of professionalism; altruism, accountability, excellence, duty, honor and integrity and respect for others [7]. This framework of medical professionalism has been considered to be applicable in other countries, [8-10] including the Arab Region [11].

Although there have been differences of opinions in regards to how to teach professionalism, $[12,13]$ another issue involves efforts to measure professionalism in the clinical environment [14, 15]. Several surveys have assessed the climate of the clinical environment, thus focusing on aspects of the environment related to professionalism, such as teamwork, warmth, respect, and social responsibility [16-18]. Alternatively, others have performed surveys asking individuals in medical training to assess the professional behaviors of their peers and instructors, as the teaching of professionalism depends heavily on role-modeling $[15,19,20]$.

Recognizing the importance of professionalism, the College of Medicine and Medical Sciences at the Arabian Gulf University (AGU) in Bahrain incorporated the teaching of professionalism into its medical school curriculum through the medium of a yearly 2-day workshop. Students participating in the workshop were asked to complete a "climate of professionalism" questionnaire that we adapted from the one developed originally by Quaintes et al., [15] and tested in other studies [21]. As learning objectives regarding the teaching of professionalism to medical students lack consensus, [22] we decided to analyze the results of this "climate of professionalism" questionnaire to inform the teaching of professionalism in subsequent years of the workshop at AGU. Accordingly, the aim of this research was for us to systematically evaluate the medical students' responses regarding professional teaching and behaviors present in the clinical areas at AGU.

\section{Methodology}

Study design A retrospective cross-sectional, questionnaire-based study. We performed all methods in accordance with relevant guidelines and regulations.
Participants Year 5 students who attended the Professionalism and Ethics workshop for the academic years 2016-2017. 2017-2018, 2018-2019, and 2019-2020.

\section{Setting - the teaching of professionalism}

Studying medicine at the Arabian Gulf University (AGU) spans over six years where students pass through a preclinical phase that includes years $1-4$ and a clinical phase that includes years 5 and 6 . In the preclinical phase, students learn about different components of professionalism as part of their weekly problem-based learning (PBL) tutorials. In addition, they attend a half/day professionalism course in the second year. In the clinical phase, an additional mandatory two-day workshop was added to the curriculum in 2016 where students, residents and faculty discuss the main principles and values of professionalism. This workshop employed active learning techniques consisting of "think-pair-share", videos, polling, and small group discussions of common clinical cases faced in their daily practice, which were then followed by large group discussions.

\section{Questionnaire}

We adapted the "climate of professionalism" questionnaire from Quaintes and colleagues [15]. The questionnaire consists of two parts. The first part assesses the students' perceptions of the frequency of professionalism practices during their clinical years. This part consists of 11 different professional and unprofessional behaviors in the clinical environment for three different target groups: medical students, residents, and faculty. The response choices included: "mostly", "sometimes", and "rarely". Thus, there was a total of 36 items. Examples of these items include the following: students/residents/faculty "advocate for the well-being of patients, students, colleagues, the community and/or the medical profession" and students/residents/faculty "complain about professional obligations."

The second part elicit students' perceptions regarding the frequency with which their professors/supervisor/attending physicians taught and modeled ten different professional behaviors over the past year. Response choices included: "mostly", "sometimes", and "rarely". Thus, there was a total of 30 items. Both parts of the questionnaire are available as supplementary files (1).

\section{Distribution of questionnaires}

We distributed the self-administered questionnaire to the medical students via the Moodle online learning platform after they attended the yearly two-day workshop in Professionalism. Responses were collected anonymously. 


\section{Statistical analysis}

From the items in Part I of the questionnaire, we calculated a total "professionalism behavior" score for each group (medical students, resident, and faculty) by assigning points to the following responses: three points to "mostly", two points to "sometimes", and one point to "rarely". Negatively worded professionalism behaviors were reverse scored so that high scores reflected more positive behaviors. The range of these scores for each group is 11-33. Higher scores indicate higher perceptions of professional behaviors.

From the 11 items in Part I of the questionnaire, we also calculated subscale scores reflecting different professionalism constructs adapted from the ABIM definition of professionalism [7]. These include the dimensions of a) Respect/Caring/Compassion/Altruism, b) Honesty/integrity,

c) Accountability/Responsibility, and d) Duty/Service/ Excellence. The professionalism behaviors associated with each of these subscales are revealed in the Table 1 . This table also shows the range of points assigned to each subscale, which was based on the above-mentioned rubric that we used to calculate the total "professionalism behavior" score.

We performed a Cronbach alpha (coefficient alpha) on the entire scale to check the internal consistency. Our analysis showed an overall Cronbach alpha of 0.60 , suggesting that the questionnaire is sufficiently reliable for further analyses. Cronbach alpha also revealed that no item if deleted would improve the overall consistency.

Table 1 Professionalism behaviors associated with each subscale

Subscale 1 Respect/Caring/Compassion/Altruism (score range: 3-9)

Show disrespect to patients, students, faculty, staff, or other healthcare personnel.

Show respect and compassion toward patients, students, faculty, staff or other healthcare personnel.

Advocate for the well-being of patients, students, colleagues, the community and/or the medical profession.

Subscale 2 Honesty/integrity (score range: 3-9)

Make selves look good at the expense of others.

Complain about professional obligations.

Lie to patients, professors, colleagues/peers or in the medical record.

Subscale 3 Accountability/responsibility (score range: 2-6)

At times hide their medical mistakes from their colleagues and the patients.

Ignore the unprofessional behavior of others.

Subscale 4 Duty/Service/Excellence/Altruism (score range: 3-9)

Exceed expectations inpatient care, class, conferences, and/or rounds.

Finish their work and help others finish theirs.
For the 10 items in Part II of the questionnaire, we calculated a total score for "faculty's teaching and modeling professional behaviors" by assigning points to the following responses: three points to "mostly", two points to "sometimes", and one point to "rarely". The range of scores is $10-30$.

We analyzed the data by using the Statistical Package for Social Sciences (SPSS) - version 26. We used descriptive analyses for all the data. We used a one-way Analysis of Variance (ANOVA) to test for mean differences between the three groups and also between the different academic years, followed by multiple testing comparisons with Bonferroni correction to examine pairwise comparisons. Statistical significance was at the level of $p<0.05$.

\section{Results}

From the four academic years, a total of 520 students completed the questionnaires; 120 students were from the academic 2016/2017; 135 students from the academic year 2017/2018, 149 students from the academic year 2018/2019, and 116 were from the academic year 2019/2020.

Table 2 shows the students' frequency rating with which they observed each of the professional behaviors of medial students, residents, and faculty in a clinical environment. The ratings represent the mean cumulative percentages of all four academic years. Professional behaviors that the medical students rated $>50 \%$ for the "mostly" observed category for all three groups included: "Show respect and compassion toward patients, students, faculty, staff or other healthcare personnel" and "show respect and compassion toward patients, students, faculty, staff or other healthcare personnel".

Unprofessional behaviors rated $>30 \%$ for the "mostly" observed category for all three groups included: "Show disrespect to patients, students, faculty, staff or other healthcare personnel"; "lie to patients, professors, colleagues/peers or in the medical record", and "at times hide their medical mistakes from their colleagues and the patients".

Table 3 shows the mean total scores of medical students' ratings of professional behaviors of medical students, residents, and faculty for each academic year. As the maximum total score is 33 , all of the mean total scores for all groups and for all four years were approximately $60 \%$ of the total maximum Professionalism score.

For the academic years $2017 / 2018$ and $2018 / 2019$, the medical students had mean total scores that were significantly greater than the groups comprised "residents" and "faculty". This difference was not present for the academic years 2016/2017 and 2019/2020.

Table 4 shows the mean subscale scores representing the four different professionalism behavior constructs 
Table 2 Participants' rating of the frequency they observed members in each group exhibiting each behavior during the past year. Ratings represents cumulative data for all four academic years Total $n$ (all four years) $=520$

\begin{tabular}{|c|c|c|c|c|c|c|c|c|c|}
\hline \multirow[t]{2}{*}{ Professionalism Behaviors } & \multicolumn{3}{|c|}{ Medical Students } & \multicolumn{3}{|c|}{ Residents } & \multicolumn{3}{|l|}{ Faculty } \\
\hline & $\begin{array}{l}\text { Mostly } \\
\%\end{array}$ & $\begin{array}{l}\text { Sometimes } \\
\%\end{array}$ & $\begin{array}{l}\text { Rarely } \\
\%\end{array}$ & $\begin{array}{l}\text { Mostly } \\
\%\end{array}$ & $\begin{array}{l}\text { Sometimes } \\
\%\end{array}$ & $\begin{array}{l}\text { Rarely } \\
\%\end{array}$ & $\begin{array}{l}\text { Mostly } \\
\%\end{array}$ & $\begin{array}{l}\text { Sometimes } \\
\%\end{array}$ & $\begin{array}{l}\text { Rarely } \\
\%\end{array}$ \\
\hline $\begin{array}{l}\text { 1. Show disrespect to patients, students, faculty, staff or } \\
\text { other healthcare personnel. }\end{array}$ & 67 & 20 & 12 & 44 & 47 & 9 & 49 & 37 & 14 \\
\hline $\begin{array}{l}\text { 2. Advocate for the well-being of patients, students, col- } \\
\text { leagues, the community and the medical profession. }\end{array}$ & 44 & 48 & 8 & 49 & 43 & 8 & 48 & 35 & 17 \\
\hline 3. Make selves look good at the expense of others. & 29 & 49 & 23 & 32 & 53 & 15 & 36 & 44 & 20 \\
\hline $\begin{array}{l}\text { 4.Exceed expectations in patient care, class, conferences } \\
\text { and/or rounds. }\end{array}$ & 11 & 67 & 22 & 27 & 60 & 13 & 30 & 61 & 10 \\
\hline 5. Finish their work and help others finish theirs. & 33 & 47 & 20 & 36 & 46 & 18 & 25 & 53 & 22 \\
\hline 6. Complain about professional obligations. & 24 & 49 & 27 & 34 & 56 & 10 & 41 & 44 & 15 \\
\hline $\begin{array}{l}\text { 7. Lie to patients, professors, colleagues/peers or in the } \\
\text { medical record. }\end{array}$ & 48 & 39 & 12 & 57 & 36 & 7 & 59 & 31 & 10 \\
\hline $\begin{array}{l}\text { 8. Show respect and compassion toward patients, } \\
\text { students, faculty, staff or other healthcare personnel. }\end{array}$ & 69 & 26 & 4 & 57 & 35 & 8 & 56 & 35 & 9 \\
\hline $\begin{array}{l}\text { 9. At times hide their medical mistakes from their } \\
\text { colleagues and the patients. }\end{array}$ & 38 & 49 & 13 & 39 & 48 & 13 & 34 & 50 & 16 \\
\hline 10. Ignore the unprofessional behavior of others. & 15 & 58 & 27 & 28 & 61 & 11 & 40 & 41 & 20 \\
\hline 11. Do just enough to get by in patient care. & 12 & 52 & 36 & 17 & 53 & 31 & 15 & 59 & 26 \\
\hline
\end{tabular}

for each of the groups and for each of the four academic years. For the subscale Respect/Caring/Compassion/Altruism, all of the mean scores were approximately $55 \%$ of the maximum score of 6 . For the subscale Honesty/ integrity, all of the mean scores were approximately $65 \%$ of the maximum score of 9. For the subscale Accountability/Responsibility, all of the mean scores were approximately $65 \%$ of the maximum score of 6 . Finally, for the subscale Duty/Service/Excellence, all of the mean scores were approximately $68 \%$ of the maximum score of 9 .

For all four years, the medical student group had mean subscale scores for "Honesty/Integrity" that were significantly higher compared with the other two groups. For the last three academic years, the medical student group had mean subscale scores for "Duty/Service/Excellence" that were significantly higher compared with the other two groups. Finally, for the last two academic years, the medical student group had mean subscale scores for
"Accountability/responsibility" that were significantly higher compared with the other two groups. In contrast, for the last two academic years, the faculty group had mean subscale scores for "Respect/Caring/Compassion/ Altruism" that were significantly higher compared with the other two groups.

Table 5 shows the medical students' perceptions of faculty's teaching and modeling professionalism behaviors. The ratings represent the mean cumulative percentages of the combined four academic years. More than $40 \%$ of the medical students rated "mostly" the following observed teaching behaviors of faculty: "acts professionally in relating to patients, students, colleagues and staff"; teaches about professionalism"; "is a good role model of professionalism for me to emulate"; and "sets clear expectations for student's professional behavior". However, at least $25 \%$ of the medical students rated "rarely" the following two teaching behaviors: "after describing the way a student should relate to a patient in a

Table 3 Mean TOTAL scores of participants' rating of professional behaviors of medical students, residents, and faculty (maximum total score $=33$ )

\begin{tabular}{lllll}
\hline & Medical Students & Residents & Faculty & ANOVA \\
\hline Year 2016-2017 $n=120$ & $20.31 \pm 3.26$ & $19.38 \pm 3.11$ & $19.62 \pm 3.27$ & 0.07 \\
Year 2017-2018 $n=135$ & $20.24 \pm 3.42$ & $19.3 \pm 3.21$ & $19.39 \pm 3.3$ & 0.04 \\
Year 2018-2019 $n=149$ & $19.93 \pm 3.11$ & $18.95 \pm 2.98$ & $19.23 \pm 3.12$ & 0.02 \\
Year 2019-2020 $n=116$ & $20.18 \pm 2.96$ & $19.31 \pm 3.14$ & $19.59 \pm 3.27$ & 0.10 \\
\hline
\end{tabular}


Table 4 Mean subscale scores of participants' rating of professional behaviors of medical students, residents, and faculty

\begin{tabular}{|c|c|c|c|c|}
\hline & Medical Students & Residents & Faculty & ANOVA \\
\hline \multicolumn{5}{|l|}{ Year 2016-2017 $(n=120)$} \\
\hline Subscale 1 Respect/Caring/Compassion/Altruism (range 3-9) & $4.59 \pm 1.33$ & $4.79 \pm 1.43$ & $4.88 \pm 1.51$ & 0.285 \\
\hline Subscale 2 Honesty/integrity (range 3-9) & $5.71 \pm 1.4$ & $5.15 \pm 1.30$ & $5.18 \pm 1.34$ & 0.002 \\
\hline Subscale 3 Accountability/responsibility (range 2-6) & $3.88 \pm 0.92$ & $3.59 \pm 1.02$ & $3.67 \pm 1.06$ & 0.079 \\
\hline Subscale 4 Duty/Service/Excellence (range 3-9) & $6.13 \pm 1.19$ & $5.85 \pm 1.29$ & $5.89 \pm 1.16$ & 0.152 \\
\hline \multicolumn{5}{|l|}{ Year 2017-2018 $(\underline{n}=135)$} \\
\hline Subscale 1 Respect/Caring/Compassion/Altruism & $4.48 \pm 1.29$ & $4.76 \pm 1.41$ & $4.84 \pm 1.57$ & 0.091 \\
\hline Subscale 2 Honesty/integrity & $5.68 \pm 1.41$ & $5.07 \pm 1.28$ & $4.97 \pm 1.30$ & 0.000 \\
\hline Subscale 3 Accountability/responsibility & $3.82 \pm 0.93$ & $3.63 \pm 0.99$ & $3.65 \pm 0.99$ & 0.206 \\
\hline Subscale 4 Duty/Service/Excellence & $6.26 \pm 1.23$ & $5.84 \pm 1.35$ & $5.92 \pm 1.19$ & 0.015 \\
\hline \multicolumn{5}{|l|}{ Year 2018-2019 $(n=149)$} \\
\hline Subscale 1 Respect/Caring/Compassion/Altruism & $4.40 \pm 1.24$ & $4.66 \pm 1.4$ & $4.84 \pm 1.53$ & 0.026 \\
\hline Subscale 2 Honesty/integrity & $5.56 \pm 1.35$ & $5.00 \pm 1.24$ & $5.04 \pm 1.28$ & 0.000 \\
\hline Subscale 3 Accountability/responsibility & $3.81 \pm 0.93$ & $3.51 \pm 0.96$ & $3.51 \pm 1.00$ & 0.010 \\
\hline Subscale 4 Duty/Service/Excellence & $6.17 \pm 1.09$ & $5.79 \pm 1.21$ & $5.84 \pm 1.08$ & 0.007 \\
\hline \multicolumn{5}{|l|}{ Year 2019-2020 $(n=116)$} \\
\hline Subscale 1 Respect/Caring/Compassion/Altruism & $4.34 \pm 1.19$ & $4.78 \pm 1.44$ & $4.87 \pm 1.51$ & 0.009 \\
\hline Subscale 2 Honesty/integrity & $5.53 \pm 1.31$ & $5.13 \pm 1.32$ & $5.16 \pm 1.36$ & 0.043 \\
\hline Subscale 3 Accountability/responsibility & $3.99 \pm 0.90$ & $3.59 \pm 1.03$ & $3.66 \pm 1.06$ & 0.005 \\
\hline Subscale 4 Duty/Service/Excellence & $6.32 \pm 1.18$ & $5.82 \pm 1.30$ & $5.89 \pm 1.16$ & 0.003 \\
\hline
\end{tabular}

difficult situation, demonstrates that behavior for students"; and "after the demonstration, asks students what they saw and solicits their comments".

Table 6 shows the mean total scores of the medical students' rating of faculty's modeling and teaching behaviors in regard to professionalism for each of the four academic years. The mean total scores for all four years were approximately $58 \%$ of the maximum score of 30 .
The mean scores between each of the four years were not statistically different.

\section{Discussion}

Within the context of an Arabic institution in the Middle East, our study reports on medical students' assessment of professional behaviors of their peers (medical students), residents and faculty, as well as their

Table 5 Participants' rating of faculty in regard to professionalism. Ratings represents cumulative data for all four academic years. Total $n=520$

\begin{tabular}{|c|c|c|c|}
\hline Professionalism Teaching Behaviors & $\begin{array}{l}\text { Mostly } \\
\%\end{array}$ & $\begin{array}{l}\text { Sometimes } \\
\%\end{array}$ & $\begin{array}{l}\text { Rarely } \\
\%\end{array}$ \\
\hline 1. Acts professionally in relating to patients, students, colleagues and staff. & 72 & 28 & 1 \\
\hline 2. Teaches about professionalism. & 47 & 42 & 11 \\
\hline 3. Discusses his/her own strivings toward professionalism and his/her own shortcomings productively and sensitively. & 34 & 53 & 13 \\
\hline 4. Creates an environment of warmth and mutual respect in relating with students. & 38 & 50 & 12 \\
\hline 5. Is a good role model of professionalism for me to emulate. & 41 & 43 & 16 \\
\hline 6. Sets clear expectations for student's professional behavior. & 41 & 46 & 13 \\
\hline 7. Enforces those expectation. & 35 & 52 & 13 \\
\hline 8. Explicitly describes the way a student should relate to patient in a difficult situation. & 38 & 46 & 17 \\
\hline $\begin{array}{l}\text { 9. After describing the way a student should relate to a patient in a difficult situation, demonstrates that behavior for } \\
\text { students. }\end{array}$ & 32 & 44 & 25 \\
\hline 10. After the demonstration, asks students what they saw and solicits their comments. & 29 & 44 & 27 \\
\hline
\end{tabular}


Table 6 Mean Total scores of participants' rating of faculty's modeling and teaching behaviors in regard to professionalism. Maximum score $=30$.

\begin{tabular}{ll}
\hline Academic Year & Mean Overall Score \\
\hline Year 2016-2017 $n=120$ & $17.12 \pm 4.24$ \\
Year 2017-2018 $n=135$ & $17.62 \pm 4.44$ \\
Year 2018-2019 $n=149$ & $17.42 \pm 4.08$ \\
Year 2019-2020 $n=116$ & $17.51 \pm 4.33$ \\
& $\boldsymbol{P}=\mathbf{0 . 8 1}$ \\
\hline
\end{tabular}

assessment of the teaching and modeling behaviors of the faculty. For all four academic years, the mean total Professional Behavior score was approximately $60 \%$ of the maximum possible score for all three targeted groups. This result is lower compared with similar surveys that reported on medical students' or residents' assessment of professional behaviors of peers or faculty. For example, in two studies conducted in Western universities, Arnold and colleagues and Quaintance and associates, using a similar survey, reported mean score percentages of 77.4 and $75.1 \%$, respectively $[15,23]$. In a study involving residents in a family medicine program at a Qatar university, Salem and associates showed that their mean total score percentage of professionalism was $70 \%$ [19]. Finally, Salem et.al, reported a mean score percentage of peer assessment of residents' professionalism at an Egyptian university to be $71 \%$ [20]. While the latter two studies used questionnaires that differed from the one we used in this study, we measured similar professionalism constructs, which adds some credibility to comparing our scores to their scores.

Reasons that can explain the lower mean total Professional scores that we obtained at the AGU could include an excessive workload of students, residents, and faculty that could have an indirect negative effect on fostering professional behaviors. Workload and amount of direct involvement of the attendings in the clinical environment might have also limited the time for rolemodeling. Finally, although AGU instituted a two-day workshop on professionalism for Year-5 students, a more intensive curriculum might be needed throughout all six years of the medical curriculum that also elicits the involvement of the faculty. This conclusion gains support from our finding showing that the ratings of the professional behaviors of the three groups remained unchanged during the four academic years despite the introduction of the workshop on professionalism. Qualitative studies are needed to further explore the reasons for these lower scores compared with other Arabic universities.

An interesting finding was that the medical students rated the professional behaviors of their peers, i.e., medical students, higher than those of residents and faculty in two of the academic years. While difficult to attach significance to these results (which may reflect positive bias towards their peers), it might suggest that the degree of professionalism declines as one passes through the academic ranks. In a study involving more than 10, 000 students at Doctor of Osteopathic granting medical schools in the U.S., Hojat and colleagues observed a statistically significant decline in empathy scores when comparing students in the preclinical (years 1 and 2) and the clinical (years 3 and 4) phases of medical school $(P<.001)$; however, the magnitude of the decline was small [24].

Additional evidence for a decline in empathy during medical training comes from the study performed by Baingana and associates, who conducted focus group discussions with 49 health professions undergraduate students (Years 1-5) from the 2008/2009 academic year at Makerere University College of Health Science [25]. Their results showing a variability in the way first- and fifth-year students conceptualized professionalism was emblematic of a loss of idealism. The authors hypothesized that the hidden and informal curricula had a negative impact on professionalism. In a qualitative study, Brown and colleagues showed that the hidden curriculum impacted negatively on professionalism and acted through role modeling, organizational culture, stereotyping and professional dress [26]. The students in the study also described their formal curriculum as being inadequate, as it consisted of one formal course that merely taught them how to "behave". Students identified role models as being essential to the development of professionalism and their recommendations included the publication of norms of professional behaviors and the institution of training activities consisting of workshops and seminars.

Regarding the results of the subscales reflecting the different professionalism constructs, our results showed that for several of the academic years, medical students had higher mean scores for the domains "Honesty/Integrity" and "Accountability/Responsibility" compared with the other two groups. However, the mean score for the domain of "Honesty/Integrity" is lower than scores observed for a similar construct in the studies performed in Qatar and Egypt [19, 20].

In contrast, faculty had higher mean total scores for Respect/Caring/Compassion/Altruism compared with the other two junior groups. One could hypothesize that exhibiting professional behaviors related to "Respect/ Caring/Compassion/Altruism" may require additional years of patient contact for doctors in training to achieve enhanced development of this professionalism construct.

In regard to faculty's "teaching and modeling" behaviors, the mean total scores of medical students' rating of their faculty's teaching and modeling professionalism 
behaviors for all four years were shown to be only slightly more than half of the achievable maximum score, which is considerably lower than that observed in the study by Quaintance and colleagues, where the comparable score regarding student assessment of professionalism teaching was above $80 \%$ of the maximum [15]. The low scores given by the medical students at AGU regarding teaching behaviors of the faculty is mirrored by the findings obtained by Adkoli and colleagues [27]. These investigators used a qualitative approach consisting of 10 focus group discussions to elicit the views of final year medical students, interns, and residents to explore aspects of professionalism at the University of Dammam, Kingdom of Saudi Arabia. The participants at the University of Dammam considered very few teachers as serving as a positive role models and that professionalism was not taught or assessed.

Quaintance and associates hypothesized that "faculty who teach professionalism may behave more professionally" and in their study involving medical students, the students' ratings of their faculty's professionalism behaviors were positively correlated with their ratings of the faculty teaching professionalism [15]. Hence, there was a particularly strong relationship between the faculty teaching professionalism and exhibiting professionalism behaviors as perceived by the students [15]. In our study, we observed qualitatively and quantitatively that in general, the teaching of professionalism by the faculty was "mixed", as rated by the students, which might have contributed to the students' moderate ratings of the faculty demonstrating professional behaviors.

The structure of our study tool mirrored the a priori attributes of professionalism that include accountability, altruism, duty, excellence, honesty and integrity and respect, which are based on the ABIM domains influenced by Western culture. However, professionalism is culturesensitive and any tool used to measure its constructs in the clinical situations should reflect the cultural context. To confirm the applicability of the tool we used in this study to the Arabic context, we refer to the study performed by Abdalla and colleagues who sought to determine the pre-clerkship medical students' perceptions of medical professionalism. These investigators distributed an online survey to 300 medical students (years 1-3) attending the College of Medicine at University of Sharjah, United Arab Emirates (UAE) [28]. Participants were asked to describe an official doctor-patient encounter that they had experienced in a health-care setting and to highlight the professional behaviors in that encounter. The behaviors that the students mentioned covered all aspects of the ABIM Physicians Charter, which supports the appropriateness of applying the ABIM professionalism constructs to the Arab Region.
Two other studies showed the influence of the Arabic setting on medical professionalism constructs. One included the efforts of Al-Eraky and associates who aimed to formulate a professionalism framework for healthcare providers as interpreted by local medical professionals in Arabian countries [29]. These investigators recruited a purposive sample of 17 experts from diverse disciplines to participate in a Delphi study consisting of three rounds. Their panel validated the appropriateness of the six ABIM domains to the Arabian context but further proposed professional autonomy as an additional professionalism construct. Ho and colleagues investigated the applicability of the Western framework of professionalism to the local context in Qatar [30]. These investigators conducted 6 focus groups with 43 clinicianeducators practicing at Hamad Medical Corporation in Doha, Qatar and while the participants generally expressed agreement with the applicability of the ABIM's charter's professionalism constructs to their context, they desired to enlarge the scope of patient autonomy to include family autonomy.

\section{Limitations}

Our study had several limitations. First, one can theorize a selection bias in our study as the students who completed the questionnaire were those who attended the 2day professionalism workshop and hence might have been more interested in professionalism than those who failed to attend. However, while attendance was optional for the first two academic years, it was mandatory for the latter two years and our results did not show any significant differences between the academic years. Another limitation was that the study relied on the subjective observations of the medical students, which might have been largely dependent on their memory. Finally, the demographical profile of the student body might limit its generalizability to other Arabic Universities. A major strength of this study is the inclusion of four different academic years cohorts in the analysis and the adaptation of a previous validated tool.

\section{Conclusions}

This study provides valuable information to improve medical students' experiences regarding the teaching of professionalism. Specifically, we will utilize our findings to a) discuss with the Faculty current approaches toward the teaching and modeling of Professionalism at the Arabian Gulf University College of Medicine and Medical Sciences and b) discuss with the faculty regarding implementation of changes in both the formal and informal curriculum throughout the basic science and clinical years to enhance professionalism teachings and behaviors. Our results also have policy implications on faculty recruitment, development, curriculum reform as well as 
further discussions regarding the influence of the organizational climate that supports professionalism.

Specifically, we recommend the following steps:

- Have the faculty perform a self-assessment of their teaching and demonstration of professionalism.

- Discuss curriculum reform and how professionalism can be further emphasized throughout medical school training.

\section{Supplementary Information}

The online version contains supplementary material available at https://doi. org/10.1186/s12909-020-02464-z

\section{Additional file 1}

\section{Acknowledgments}

None.

\section{Authors' contributions}

HAG contributed to the idea of the study, analyzed and interpreted the data and was a major contributor in writing the manuscript. HAJ analyzed and interpreted the data and contributed to writing the manuscript. HS contributed to the idea of the study, analyzed and interpreted the data and was a major contributor in writing the manuscript. All authors read and approved the final manuscript.

\section{Funding}

Not applicable.

\section{Availability of data and materials}

The datasets used and analyzed during the current study are available from the corresponding author on reasonable request.

\section{Ethics approval and consent to participate}

Ethical approval was obtained from the following ethics committees: - The Research and Ethics Committee at the College of Medicine and Medical Sciences at the Arabian Gulf University; Project number: E20-PI-01/20 - The Institutional Review Board at the University of Maryland Baltimore (HP00093211)

The author (HJS) at the University of Maryland only received aggregate deidentified data, and hence the IRB made a designation that he was involved in non-human subject research.

A waiver of informed consent was obtained for this secondary analysis of existing data. The waiver was justified as 1) the research involved no greater than minimal risk as the data set was deidentified; 2) it was impracticable to conduct the research without the waiver; and 3) the waiver will not adversely affect the rights and welfare of the subjects. Finally, the privacy of the medical students was assured, as the questionnaires were collected anonymously.

\section{Consent for publication}

N/A

\section{Competing interests}

All authors declare that they do not have any competing interests.

\section{Author details}

'Department of Psychiatry, Arabian Gulf University, Manama, Kingdom of Bahrain. ${ }^{2}$ Department of Medicine, University of Maryland Baltimore, Baltimore, MD 21201, USA.
Received: 27 October 2020 Accepted: 14 December 2020

Published online: 08 January 2021

\section{References}

1. Starr P. The social transformation of American medicine. New Yorfk: Basic Books; 1984.

2. Brennan MD, Monson V. Professionalism: good for patients and health care organizations. Mayo Clin Proc. 2014;89(5):644-52.

3. Cruess SR. Professionalism and medicine's social contract with society. Clin Orthop Relat Res. 2006;449:170-6.

4. Siegler M. Identifying the ethical aspects of clinical practice. Bull Am Coll Surg. 1996;81(11):23-5.

5. Arawi TA. The muslim physician and the ethics of medicine. Journal of the IMA. 2010;42(3):111-6

6. DeAngelis CD. Medical professionalism. JAMA. 2015;313(18):1837-8.

7. American Board of Internal Medicine. Project professionalism. Philadelphia, Pa: American Board of Internal Medicine; 1994.

8. Tsai TC, Lin CH, Harasym PH, Violato C. Students' perception on medical professionalism: the psychometric perspective. Med Teach. 2007;29(2-3): 128-34.

9. Aramesh K, Mohebbi M, Jessri M, Sanagou M. Measuring professionalism in residency training programs in Iran. Med Teach. 2009;31(8):e356-61.

10. Suzuki N. Certification for specialists on neurology by Japanese Society of Neurology. Rinsho Shinkeigaku. 2009:49(11):745-6.

11. Al-Eraky MM, Chandratilake M. How medical professionalism is conceptualised in Arabian context: a validation study. Med Teach. 2012; 34(Suppl 1):S90-5.

12. Stockley AJ, Forbes K. Medical professionalism in the formal curriculum: 5 th year medical students' experiences. BMC Med Educ. 2014;14:259.

13. Cruess RL, Cruess SR. Teaching professionalism: general principles. Med Teach. 2006:28(3):205-8.

14. Li H, Ding N, Zhang Y, Liu Y, Wen D. Assessing medical professionalism: a systematic review of instruments and their measurement properties. PLoS One. 2017;12(5):e0177321.

15. Quaintance $\mathrm{J}$, Arnold L, Thompson GS. Development of an instrument to measure the climate of professionalism in a clinical teaching environment. Acad Med. 2008:83(10 Suppl):S5-8.

16. Cavanaugh S, Simmons P. Evaluation of a school climate instrument for assessing affective objectives in health professional education. Eval Health Prof. 1997;20(4):455-78.

17. Ells C, Downie J, Kenny N. An assessment of ethical climate in three healthcare organizations. J Clin Ethics. 2002;13(1):18-28.

18. Scott T, Mannion R, Marshall M, Davies H. Does organisational culture influence health care performance? A review of the evidence. J Health Serv Res Policy. 2003;8(2):105-17.

19. Salem M, Al-Ali A, Alm-Mutawaa N, Yousuf W, Almansouri N. P. professionalism in family medicine residency program in Qatar. World Family Med. 2018;16:4-8.

20. Salem A, Talaat W, Kamel MH, Hassan N. Assessing Professionalism among Residents: Peer and Self-assessment. Intel Prop Rights. 2015;3.

21. Spiwak R, Mullins M, Isaak C, Barakat S, Chateau D, Sareen J. Medical students' and postgraduate residents' observations of professionalism. Educ Health (Abingdon). 2014;27(2):193-9.

22. Cruess SR, Cruess RL. Teaching professionalism - why, what and how. Facts Views Vis Obgyn. 2012:4(4):259-65.

23. Arnold EL, Blank LL, Race KE, Cipparrone N. Can professionalism be measured? The development of a scale for use in the medical environment. Acad Med. 1998;73(10):1119-21.

24. Hojat M, Shannon SC, DeSantis J, Speicher MR, Bragan L, Calabrese LH. Does empathy decline in the clinical phase of medical education? A Nationwide, multi-institutional, cross-sectional study of students at DO-granting medical schools. Acad Med. 2020;95(6):911-8.

25. Baingana, et al. Learning health professionalism at Makerere University: an exploratory study amongst undergraduate students. BMC Med Educ. 2010; 10:76. https://doi.org/10.1186/1472-6920-10-76

26. Brown MEL, Coker O, Heybourne A, Finn GM. Exploring the hidden curriculum's impact on medical students: professionalism, identity formation and the need for transparency. Med Sci Educ. 2020;30:1107-21.

27. Adkoli BV, Al-Umran KU, Al-Sheikh M, Deepak KK, Al-Rubaish AM. Medical students' perception of professionalism: a qualitative study from Saudi Arabia. Med Teach. 2011;33(10):840-5. 
28. Abdalla ME, Dash NR, Shorbagi S, Ahmed MH. Preclerkship medical students' perceptions of medical professionalism in the College of Medicine-University of Sharjah: A vision to sustain success in medical education. J Educ Health Promot. 2020;9:119.

29. Al-Eraky MM, Donkers J, Wajid G, van Merrienboer JJ. A Delphi study of medical professionalism in Arabian countries: the four-gates model. Med Teach. 2014;36(Suppl 1):S8-16.

30. Ho MJ, Alkhal A, Tekian A, Shih J, Shaw K, Wang CH, Alyafei K, Konopasek L. Contextualizing the physician charter on professionalism in Qatar: from patient autonomy to family autonomy. J Grad Med Educ. 2016;8(5):719-25.

\section{Publisher's Note}

Springer Nature remains neutral with regard to jurisdictional claims in published maps and institutional affiliations.

Ready to submit your research? Choose BMC and benefit from:

- fast, convenient online submission

- thorough peer review by experienced researchers in your field

- rapid publication on acceptance

- support for research data, including large and complex data types

- gold Open Access which fosters wider collaboration and increased citations

- maximum visibility for your research: over $100 \mathrm{M}$ website views per year

At $\mathrm{BMC}$, research is always in progress.

Learn more biomedcentral.com/submissions 